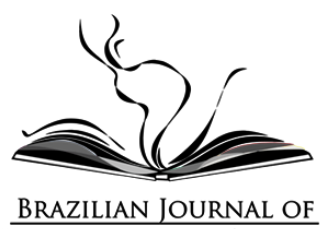

\title{
UM OLHAR LATINO-AMERICANO SOBRE A ERA TRUMP
}

\author{
A LATIN AMERICAN LOOK AT THE TRUMP ERA \\ UNA MIRADA LATINOAMERICANA A LA ERA TRUMP
}

Ricardo Neves Streich' (iD)

Universidade de São Paulo, Brasil

\begin{abstract}
Resumo: Este texto é uma resenha do livro "Geopolítica y Economía Mundial. El ascenso de China, la era Trump y América Latina" organizado por Gabriel Esteban Merino e Patricio Narodowski e publicado no segundo semestre de 2019 pelo Instituto de Investigaciones en Humanidades y Ciencias Sociales da Universidad de la Plata. A obra em questão busca analisar a partir de uma perspectiva periférica e latino-americana as dinâmicas atuais do capitalismo mundial. A grande disputa característica destas dinâmicas é a emergência político-econômica chinesa, ocorrida no século XXI, e a resposta nacionalista estadunidense, notadamente a vitória eleitoral de Donald Trump em 2016. Para analisar esta candente e complexa questão são mobilizados instrumentais teóricos de diversas áreas do conhecimento, dentre as quais a sociologia, economia, geopolítica e história. Com estas contribuições o livro ambiciona criticar as perspectivas tipicamente liberais e, assim, atualizar a perspectiva estruturalista tão cara à tradição das ciências sociais latino-americanas, especialmente no que diz respeito às categorias de "centro-periferia", "hegemonia" e "dependência".
\end{abstract}

Palavras-chave: Geopolítica, Trump, Estados Unidos, China, América Latina

Abstract: This text is a review of the book "Geopolítica y Economía Mundial. El ascenso de China, la era Trump y América Latina" organized by Gabriel Esteban Merino and Patricio Narodowski and published in the second semester of 2019 by the Instituto de Investigaciones en Humanidades y Ciencias Sociales of the Universidad de la Plata. The book seeks to analyze, from a peripheral and Latin American perspective, the current dynamics of world capitalism. These dynamics can be synthesized in the political and economical disputes between the United States and China. Thus, Donald Trump's government must be understood as a nationalist response to the Chinese emergency. In order to explain this

\footnotetext{
${ }^{1}$ Doutorando em História Econômica no Programa de Pós-graduação em História Econômica da Faculdade de Filosofia, Letras e Ciências Humanas da Universidade de São Paulo e bolsista FAPESP (n²017/17.481-2). E-mail: ricardostreich@gmail.com
} 
issue, the book criticizes the liberal perspective by updating fundamental concepts of the Latin American structuralist thinking, especially with regard to the categories of "center-periphery", "hegemony" and "dependency".

Keywords: Geopolitics, Trump, United States, China, Latin America

Resumen: Este texto es una reseña del libro "Geopolítica y Economía Mundial. El ascenso de China, la era Trump y América Latina" organizado por Gabriel Esteban Merino y Patricio Narodowski y publicado en el segundo semestre de 2019 por el Instituto de Investigaciones en Humanidades y Ciencias Sociales de la Universidad de la Plata. El libro busca analizar, desde una perspectiva periférica y latinoamericana, la dinámica actual del capitalismo mundial, especialmente las disputas políticas y económicas entre Estados Unidos y China. Así, es necesario comprender el gobierno de Donald Trump como una respuesta nacionalista a la emergencia china. Por fin, para profundizar el tema de las disputas en torno del liderazgo mundial entre Estados Unidos y China, el libro critica la perspectiva liberal actualizando conceptos fundamentales del pensamiento estructuralista latinoamericano, especialmente las categorías de "centro-periferia", "hegemonía" y "dependencia".

Palabras - claves: Geopolítica, Trump, Estados Unidos, China, América Latina

DOI:10.11606/issn.1676-6288.prolam.2020.169326

Recebido em: 01/05/2020 Aprovado em: 20/09/2020 Publicado em: 22/10/2020

As transformações da ordem econômica e política mundial, especialmente no que dizem respeito à emergência do protagonismo político e econômico alcançado pela China no século XXI, são latentes e, por isto, têm despertado uma intensa produção acadêmica nas mais variadas esferas das ciências humanas. Dentre elas, se destaca o livro organizado por Gabriel Esteban Merino e Patricio Narodowski de título "Geopolítica y Economía Mundial. El ascenso de China, la era Trump y América Latina", publicado no segundo semestre de 2019 pelo Instituto de Investigaciones en Humanidades y Ciencias Sociales da Universidad de la Plata.

A obra está divida em 12 capítulos, os quais foram escritos por 
acadêmicos ligados ao departamento de geografia da Universidad de la Plata e podem ser agrupados, para os fins expositivos desta resenha, em quatro blocos. O primeiro destes blocos consiste na delimitação conceitual e histórica que orienta as análises empíricas realizadas no decorrer do livro. Assim, fazem parte do primeiro bloco os capítulos 1 ("Hacia una geografía económica y política de la complejidad" assinado por Gabriel Esteban Merino e Patricio Narodowski), e 2 ("El fin del siglo norteamericano la irrupción de China y los ciclos en la periferia" de Patricio Narodowski).

Do ponto de vista teórico, este primeiro bloco caracteriza a perspectiva interdisciplinar que permeia a obra. Trata-se, pois, de somar à geopolítica e à economia (indicadas já no título do livro) as contribuições da história e da sociologia de modo a recuperar algumas categorias que andam silenciadas na produção acadêmica contemporânea. Neste sentido, pode-se observar que a estratégia de combate e crítica à visão liberal hegemônica na geopolítica, um dos objetivos do livro, consiste em resgatar e atualizar as clássicas perspectivas estruturalistas das ciências sociais latino-americanas, em especial a teoria marxista da dependência.

A teoria marxista da dependência surgiu na década de 1960 e teve como seus maiores expoentes Ruy Mauro Marini, Vânia Bambirra e Theotônio dos Santos. Esta corrente político-intelectual tinha como ambição realizar um diagnóstico das especificidades estruturais da periferia do capitalismo. Para isto, criticaram o eurocentrismo característico tanto das teorias do desenvolvimento quanto da ortodoxia soviética, pois não mais concebiam o subdesenvolvimento (e seus congêneres como "etapa feudal", "etapa colonial") como uma etapa rumo ao desenvolvimento característico dos países centrais do capitalismo. Pelo contrário, desenvolvimento e subdesenvolvimento (centro e periferia, portanto) "passam a ser concebidos como aspectos diferentes do mesmo processo universal" (DOS SANTOS, 2000, p. 19) que se relacionam dialeticamente. 
Desta forma, a obra organizada Gabriel Esteban Merino e Patricio Narodowski recupera dois dos pressupostos característicos da teoria marxista da dependência para realizar sua crítica à perspectiva liberal. $\bigcirc$ primeiro, é a preocupação em pensar os problemas do capitalismo contemporâneo a partir de uma perspectiva que almeja a totalidade, a qual demanda a interdisciplinaridade tão característica do livro. O segundo ponto é que o olhar para esta totalidade é apreendido a partir da condição da periferia na ordem internacional, em especial a latino-americana como se verá ao final do livro.

A recuperação desses pressupostos permite, então, uma atualização da teoria marxista da dependência, justamente por conta da ambição de explicar as transformações sistêmicas - e, consequentemente, seus impactos na periferia, em especial na América Latina - da ascensão da China no cenário mundial e da vitória de Donald Trump nas eleições de 2016 para a presidência dos Estados Unidos da América. Por esta razão, o objetivo do primeiro bloco parece ser o de situar conceitos como "hegemonia" e "relações centro-periferia" de modo a demarcar a lógica contemporânea do sistema das relações internacionais. Ou seja, o bloco busca delimitar, de forma conceitual e histórica, a formação do sistema político internacional capitaneado pelos Estados Unidos, além de expor as estratégias de exercício do poder características desse processo (Cf. MERINO; NARODOWSKI, 2019a, p. 13).

O segundo bloco, por sua vez, lança luzes ao cenário político em que ocorreu a vitória eleitoral de Donald Trump, cujas posições nacionalistas representam uma inflexão na lógica que rege a política interna e externa dos Estados Unidos. Neste sentido, o objetivo deste bloco é justamente escrutinar econômica, política e socialmente a história desta lógica subvertida por Trump. Assim, o bloco é composto pelos capítulos 3 ("El escenario de la campaña electoral del 2015 y Trump en acción" por Gabriel Esteban Merino e Patricio Narodowski), 4 ("Globalistas vs Americanistas" assinado por Gabriel Esteban Merino), 5 ("Las bases ideológicas de los 
Estados Unidos de América" de Darío Saavedra e Federico Esquiroz) e 6 ("Las disputas y las alianzas entre los países desarrollados. Un recorrido hasta nuestros días.", escrito por Héctor Adolfo Dupuy e Juan Cruz Margueliche).

Os parâmetros que orientam a política interna e externa dos Estados Unidos são analisados no livro a partir de perspectivas econômicas, geopolíticas e históricas e consistem, em linhas gerais, em um par dicotômico, a saber: "americanismo x globalismo" (Cf. MERINO, 2019, pp. 81-108). O primeiro termo diz respeito à perspectiva dos governos estadunidenses se fecharem ao mundo e priorizarem assuntos referentes à política interna. Já o segundo termo, preponderante no pós-guerra, traduz a perspectiva dos governantes estadunidenses ativamente exercerem o protagonismo que o arranjo econômico e político do pós-guerra lhes proporcionaram.

É interessante observar que esse debate não ocorre no abstrato, já que o desprezo pelos espaços multilaterais de negociação política e econômica propagado pela posição "americanista" se fundamenta nos custos que são exigidos de qualquer player que se proponha a ocupar o papel de liderança global. Daí a necessidade de analisar as posições nacionalistas de Trump e a força sociopolítica que ele foi capaz de mobilizar como resposta à ascensão chinesa, país bastante empenhado em arcar com os custos de construir uma posição de liderança, como afirmam os autores Gabriel Esteban Merino e Patricio Narodowski (2019b, p. 67, tradução nossa) :

Uma questão geopolítica central é a ascensão da China, que desafia estrategicamente a condição dominante do polo anglo-americano de poder liderado pelos EUA. Para as forças americanas-nacionalistas comandadas por Trump, é alarmante a nova inserção do gigante oriental na América Latina, quintal da potência norte e a partir do qual ela pode projetar sua potência mundial (aqui há diferenças com as forças globalistas).

O terceiro bloco, por sua vez, consiste numa análise empírica da disputa hegemônica entre Estados Unidos decadente e China ascendente. 
O conflito é abordado em diversos âmbitos, com especial atenção às questões econômicas, políticas e militares como se pode observar nos capítulos 7 ("Los jugadores y los conflictos", assinado por Rocio Jaimarena, Gabriel Esteban Merino e Patricio Narodowski), 8 ("EEUU y China: aporte al debate sobre los diferenciales de complejidad entre ambos" de Ximena Valentina Echenique Romero e Patricio Narodowski) e 9 ("La hegemonía condicionada en las instituciones económicas" por Karina Liliana Angeletti e Patricio Narodowski).

A grande tese deste bloco é que a crise econômica de 2008 entendida como crise de sobreacumulação de capital, além de seus problemas de realização decorrentes da financeirização (Cf. JAIMERENA; MERINO; NARODOWSKI, 2019, p. 183) - fatores que aceleraram o processo de decadência dos Estados Unidos e ascensão chinesa, sendo a eleição de Trump, conforme já assinalado, uma tentativa de resposta à crise da hegemonia estadunidense.

É necessário salientar, contudo, os avanços econômicos, políticos e militares da China ainda não são suficientes para colocá-la na condição de centro hegemônico mundial, como demonstra a análise dos organismos financeiros multilaterais. Dessa forma, Karina Liliana Angeletti e Patricio Narodowski (2019, p.207) defendem que o processo de crescimento (e complexificação) econômico chinês, justamente ao movimentar toda a economia global, acabou por reforçar o caráter de dominância dos Estados Unidos no que diz respeito ao sistema monetário internacional. Assim, por mais que a China já venha experimentando acordos comerciais que dispensem o dólar (especialmente com a Rússia), é fato que, a título de exemplo, as alterações nas taxas de juros dos Estados Unidos ainda são capazes de influenciar a economia global em uma escala inalcançável para o sistema monetário chinês.

Os efeitos dessa disputa na América Latina são justamente o tema do quarto e último bloco do livro, composto pelos capítulos 10 ("La estrategia 
del TLCAN y la relación de EEUU y México" por Gabriel Estaban Merino e Damian Ariel Giammarino), 11 ("La Alianza del Pacífico (AP) y el Acuerdo Transpacífico (TPP), entre globalistas y americanistas" de Juan Andrés Amor, Andrés Leaño e Gabriel Esteban Merino) e 12 ("Los gobiernos nacional-populares de la región en el siglo XXl" assinado por Gabriel Esteban Merino e Soledad Stoessel).

Sobre o tema é fundamental apontar que a leitura do livro não se limita a apresentar a América Latina como mero objeto na estratégia chinesa e ou na estadunidense. Ou seja, a obra busca pensar como os governos latino-americanos - sem desconsiderar as particularidades de cada país da região - se posicionam na disputa entre as duas potências econômicas do século XXI.

Neste sentido, é muito interessante observar a preocupação dos organizadores em dar espaço às especificidades do México (governado pelo PAN, partido liberal de cunho conservador, entre os anos 2000 e 2012 e pelo fisiologismo histórico do PRI, entre 2012 e 2018), e às da América do Sul, cujos maiores países (em termos econômicos e populacionais) foram governados por partidos de centro-esquerda nos primeiros 15 anos do século XXI, período conhecido como "onda rosa".

Sobre a América do Norte, Gabriel Esteban Merino e Damian Ariel Giammarino (2019, pp. 219-220) demonstram que a dependência da economia mexicana relativa aos EUA, decorrente do histórico imperialista estadunidense e amplificado pela proximidade entre ambos os países, não permitiu que a China lograsse estreitar vínculos com o México, tal qual ocorreu no sul do continente. Por isto, no processo de renegociações dos termos do NAFTA, exigência de Donald Trump, o México teve pouco espaço de barganha e as novas condições impostas por Trump, demonstrando seu ímpeto nacionalista, aprofundaram a tendência a um maior grau de desintegração e dependência da indústria mexicana.

Na América do Sul, a eleição de Trump coincide com o fim dos 
governos progressistas da "onda rosa". Deste lado do equador, os governos de direita que se encontram no poder trouxeram de volta o ideário neoliberal e o alinhamento econômico-diplomática aos Estados Unidos. Contudo é fundamental apontar que esse processo de (re)alinhamento geopolítico e econômico com os Estados Unidos não ocorreu de maneira linear, justamente por conta do ritmo das disputas internas que determinam as políticas de cada país (Cf. MERINO; STOESSEL, 2019, pp. 248-258).

Ademais, é interessante notar que a importância que a perspectiva americanista de Trump atribui à América Latina não tem se traduzido em aproximações diplomáticas e de softpower, mas sim nas iniciativas de inviabilizar - no sentido de realizar ameaças de cunho diplomático, econômico e até mesmo militar — os governos que ativamente se colocam como adversários de Washington, como resumem os organizadores do livro:

\begin{abstract}
Enquanto isso, Trump ainda não viajou para a América Latina e foi o primeiro presidente americano a não comparecer a uma Cúpula das Américas em quase 25 anos, negligenciando um espaço que as forças nacionalistas-americanas consideram vitais para reconstituir sua hegemonia global. A isso, devemos acrescentar que a política na região se concentra fundamentalmente em sancionar/destituir/confrontar governos não afins (há um novo eixo do mal para Washington, composto pela tríade Venezuela, Cuba e Nicarágua), em exacerbar ações disciplinares e em bloquear na região aos poderes adversários, em vez de construir laços positivos. Ou seja, "castigo sem incentivo" (MERINO; NARODOWSKI, 2019b, p.68, tradução nossa).
\end{abstract}

Observa-se que a passagem acima indica uma das contradições fundamentais do governo de Trump. Tal qual propugnado pela tendência "americanista" mencionada anteriormente, o trumpismo deseja exercer a hegemonia político-econômica do mundo sem arcar com os custos exigidos pelo protagonismo. Em sentido contrário, o governo chinês se mostra decidido a investir e arcar com os custos exigidos para ocupar a posição de liderança no cenário global. É por isso que a análise destas contradições entre as posturas dos governos de Estados Unidos e China se tornam mais relevantes nos marcos da atual pandemia - vale lembrar que 
a publicação do livro é anterior ao aparecimento do novo coronavírus -, a qual parece dar razão, senão catalisar, às teses presentes no livro organizado por Gabriel Esteban Merino e Patricio Narodowski. Afinal, enquanto a China foi capaz de articular uma resposta rápida ao vírus, os Estados Unidos no momento da escritura desta resenha ainda sofrem com o aumento diário de número de mortos.

Assim, ao findar a leitura do livro temos a sensação de que a virada nacionalista de Trump é um dos sintomas mórbidos, na clássica acepção gramsciana, da crise que atinge a ordem mundial pós-guerra fria desde 2008. Afinal, não seria a mesquinhez nacionalista trumpista - capaz de desviar respiradores mecânicos destinados à Europa e ao Brasil no meio da pandemia - justamente o "velho que insiste em não morrer" enquanto o "novo ainda não nasceu"?

\section{REFERÊNCIAS}

ADRIANI, Héctor Luis. Prólogo. In: MERINO, Gabriel Esteban; NARODOWSKI, Patricio (Coord). Geopolítica y Economía Mundial. El ascenso de China, la era Trump y América Latina. La Plata: IdiHCS, 2019.

ANGELETTI, Karina Liliana; NARODOWSKI, Patricio. La hegemonía condicionada en las instituciones económicas. In: MERINO, Gabriel Esteban; NARODOWSKI, Patricio (Coord). Geopolítica y Economía Mundial. El ascenso de China, la era Trump y América Latina. La Plata: IdiHCS, 2019.

DOS SANTOS, Theotônio. A teoria da dependência: balanços e perspectivas. Rio de Janeiro: Civilização Brasileira, 2000.

JAIMARENA, Rocio; MERINO, Gabriel Esteban; NARODOWSKI, Patricio. Los jugadores y los conflictos. In: MERINO, Gabriel Esteban; NARODOWSKI, Patricio (Coord). Geopolítica y Economía Mundial. El ascenso de China, la era Trump y América Latina. La Plata: IdiHCS, 2019.

MERINO, Gabriel Esteban. Globalistas vs Americanistas. In: MERINO, Gabriel Esteban; NARODOWSKI, Patricio (Coord). Geopolítica y Economía Mundial. El ascenso de China, la era Trump y América Latina. La Plata: IdiHCS, 2019.

MERINO, Gabriel Esteban; GIAMMARINO, Damian Ariel. La estrategia del TLCAN y la relación de EEUU y México. In: MERINO, Gabriel Esteban; 
NARODOWSKI, Patricio (Coord). Geopolítica y Economía Mundial. EI ascenso de China, la era Trump y América Latina. La Plata: IdiHCS, 2019.

MERINO, Gabriel Esteban; STOESSEL, Soledad. LOS gobiernos nacional-populares de la región en el siglo XXI. In: MERINO, Gabriel Esteban; NARODOWSKI, Patricio (Coord). Geopolítica y Economía Mundial. El ascenso de China, la era Trump y América Latina. La Plata: IdiHCS, 2019.

MERINO, Gabriel Esteban; NARODOWSKI, Patricio. Hacia una geografía económica y política de la complejidad. In: MERINO, Gabriel Esteban; NARODOWSKI, Patricio (Coord). Geopolítica y Economía Mundial. El ascenso de China, la era Trump y América Latina. La Plata: IdiHCS, 2019a.

MERINO, Gabriel Esteban; NARODOWSKI, Patricio. El escenario de la campaña electoral del 2015 y Trump en acción. In: MERINO, Gabriel Esteban; NARODOWSKI, Patricio (Coord). Geopolítica y Economía Mundial. El ascenso de China, la era Trump y América Latina. La Plata: IdiHCS, 2019b. 